\title{
Oxide Ceramic Matrix Composite Materials for Aero-Engine Applications: A Literature Review
}

\author{
George KARADIMAS ${ }^{1}$, Konstantinos SALONITIS \& Konstantinos GEORGARAKIS \\ Manufacturing, Cranfield University, Cranfield MK43 OAL, UK
}

\begin{abstract}
The development of aircraft gas turbine engines has extensively been required for the development of advanced materials. This complex development process is however justified by the system-level benefits in terms of reduced weight, higher temperature capability, and/or reduced cooling, each of which increases efficiency. This is where high-temperature ceramics have made considerable progress and ceramic matrix composites (CMCs) are in the foreground. CMCs are classified into non-oxide and oxide-based ones. Both families have material types that have a high potential for use in high-temperature propulsion applications. Typical oxide-based ones are based on an oxide fiber and oxide matrix (Ox-Ox). Some of the most common oxide subcategories, are alumina, beryllia, ceria, and zirconia ceramics. Such matrix composites are used for example in combustion liners of gas turbine engines and exhaust nozzles. However, until now a thorough study on the available oxide-based CMCs for such applications has not been presented. This paper focus on assessing a literature survey of the available oxide ceramic matrix composite materials in terms of mechanical and thermal properties.
\end{abstract}

Keywords. CMC; Oxide-CMC; Material classification

\section{Introduction}

Ceramic matrix composites (CMCs) are suited for thermomechanical and aerospace applications due to their damage-tolerant fracture behavior, excellent temperature stability, low density, high hardness, and good corrosion and wear resistance. Also, CMCs bring advantages in weight reduction, increase in thermal efficiency by increasing process temperatures or prolonged service life, and reduced maintenance costs $[1,2]$. These materials are considered as alternatives to nickel alloys for hot section engine applications as they offer specific advantages such as reliable performance at extreme temperatures up to $1,300^{\circ} \mathrm{C}$, significant weight savings, and no need for cooling air requirements. CMCs can be used for a few different components such as the turbine shrouds in the hot sections of engines but until now CMCs have been used mainly for static parts. Recent studies indicate that they could be used for rotating parts as well [3]. They can be classified into non-oxide (NO-CMC) and all oxide (O-CMC) ones. The main objectives of this paper include the classification of the existing oxide CMC materials, the assessment of the properties achieved, and the available aero-engine applications.

\footnotetext{
${ }^{1}$ Corresponding Author. g.karadimas@cranfield.ac.uk
} 


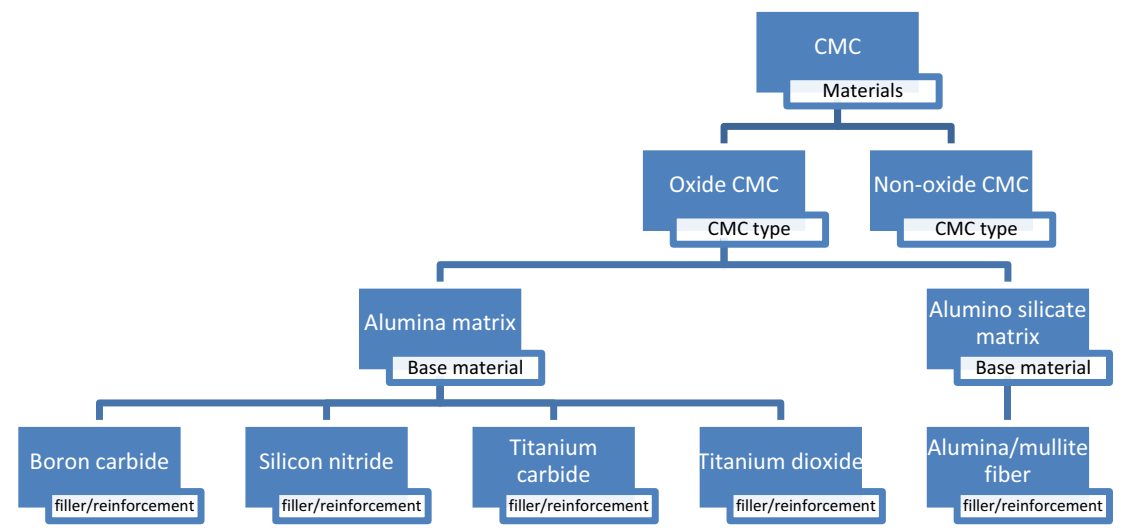

Figure 1 Oxide CMC base materials matrices and their filler/reinforcement different combinations.

\section{Classification of oxide CMCs}

Oxide CMCs demonstrate a variety of combinations (figure 1). These combinations can be grouped into oxide/oxide matrices, where both base material and filler/reinforcement are oxides or oxide/non-oxide matrices, where the base material is an oxide, and the filler/reinforcement is a non-oxide.

\subsection{Alumina Matrix Oxide CMCs}

Alumina oxide $\left(\mathrm{Al}_{2} \mathrm{O}_{3}\right)$ is an electrical insulator, with a relatively high thermal conductivity. $\mathrm{Al}_{2} \mathrm{O}_{3}$ also possesses good mechanical properties such as high hardness, high compressive strength, and good chemical and thermal stability [2]. However, its applications as a structural material have been limited due to its low fracture toughness and strength. This is due to cracks easily propagating in this ceramic and result in unpredictable failures during service $[3,4]$. On the other hand, using the alumina matrix as a base material and combine it with a range of filler/reinforcements, can result in better overall mechanical, physical, and thermal properties, allowing the end products to be used in many different applications.

- $\quad$ Alumina matrix \& Boron carbide CMCs

The literature review highlighted the use of boron carbide $\left(\mathrm{B}_{4} \mathrm{C}\right)$ particulates as reinforcement for the alumina matrix. The usual composition includes $40-50 \%$ volume percentage of $\mathrm{B}_{4} \mathrm{C}$ [6,23-25], although experimental works have been undertaken for assessing the impact of higher concentrations to such CMCs [7], indicating that the higher the $\mathrm{B}_{4} \mathrm{C}$ presence in the composite, the stronger the final material. The common manufacturing processes include pressing and sintering. $\mathrm{B}_{4} \mathrm{C}$ reinforced $\mathrm{CMCs}$ are very capable ceramic composites due to their attractive properties which include high strength and hardness, low density, neutron absorption capability, and acceptable chemical stability, making it capable to ionize radiation [5]. They can be typically used in high-temperature structural applications.

- $\quad$ Alumina Matrix \& Silicon Nitride CMCs

Silicon nitride particulates $\left(\mathrm{Si}_{3} \mathrm{~N}_{4}\right)$ as reinforcement for the alumina matrix are widely used as well [6]. Such material composition demonstrates great specific strength, hardness, and ultimate tensile strength [8]. Common manufacturing 
processes for this composite include hardening, pressing, and sintering. $\mathrm{Si}_{3} \mathrm{~N}_{4}$ properties allow for the composition of hard ceramic particles with high mechanical strength and good wear resistance [9, 23-24]. Alumina $\mathrm{Si}_{3} \mathrm{~N}_{4}$ CMCs can be used in high-temperature structural applications due to its very high heat resistance, but until now has never been reported in an aerospace application.

- $\quad$ Alumina Matrix \& Titanium Carbide CMCs

Titanium Carbides (TiC) are widely used in aero engine applications [6]. In recent studies, TiC particulate reinforcements are combined with the alumina matrix. The most common compositions include $25-30 \%$ volume percentage of TiC. Increasing $\mathrm{TiC}$ concentration in the alumina matrix can result in higher strength and in-situ healing of cracks in the surface of the composite in very high temperatures [11-12]. This is due to TiC's high specific strength and elastic modulus, as well as its high melting point and thermal conductivity [10]. However, there are only a few paper reporting $\mathrm{TiC}$ used as an $\mathrm{O}-\mathrm{CMC}$ reinforcement for aero-engine applications in the literature.

- $\quad$ Alumina Matrix \& Titanium Dioxide CMCs

The combination of alumina matrix reinforced with titanium dioxide particulate has been also reported in the literature [6,23]. The most common composition includes $10 \%$ volume percentage of $\left(\mathrm{TiO}_{2}\right)$ because $\mathrm{TiO}_{2}$ significantly lowers the microhardness/tensile strength of a material. $\mathrm{Al}_{2} \mathrm{O}_{3} / \mathrm{TiO}_{2} \mathrm{CMCs}$ present higher microhardness values than $\mathrm{TiO}_{2}$ and $\mathrm{Al}_{2} \mathrm{O}_{3}$ separately, lower thermal expansion and thermal conductivity and increased thermal shock resistance [18]. Typical applications are in crucibles, nozzles, tubes, thermocouples, port liner in autos, master molds in the glass industry, plasma and flame spraying, coatings (thermal, corrosion, and wear protection) [17].

\subsection{Aluminosilicate Matrix CMCs}

$\mathrm{Al}_{2} \mathrm{O}_{3}$ formed at the interface between the $\mathrm{Al}$, in metallic form, and aluminosilicate matrix improved the bonding strength of composites [19]. Alumina fibers or aluminosilicate (AS) fibers are mainly employed to reinforce the Oxide/Oxide CMCs, in which the matrices are mainly composed of alumina, silica, and mullite. $\mathrm{SiO}_{2}$ matrix, as a kind of potential material for high-temperature ceramics, has the advantage of low and stable dielectric constant, high chemical stability, good mechanical stability, and excellent thermal shock resistance. $\left(\mathrm{SiO}_{2}\right)$ ceramics have been successfully applied in antenna housing, aerospace engineering application, supercapacitors [20].

- $\quad$ Aluminosilicate Matrix \& Alumina/Mullite Fiber CMCs

The combination of alumina mullite fiber reinforcement and aluminosilicate matrix has been also reported in the literature [6-23]. The oxide compositions that occur are $45 \mathrm{Vf}$ woven fabric and $45 \mathrm{Vf}$ quasi-isotropic aluminosilicate/Nextel 720 . This porous mullite- $\mathrm{Al}_{2} \mathrm{O}_{3}$ composites' most used manufacturing process is through the slurry infiltration-wound (SI-W) [24-25], allowing the composite for a higher strength retention rate, which reaches $97.3 \%$. Although this composite is not applied yet in real-life applications, it can be used in the inner and outer linings of aeroengine combustion chambers, the light exhaust duct for helicopters as well as the hot end parts of the super craft nose cone [21]. This is mainly because it displays high strength, excellent oxidation resistance, and environmental stability at high temperatures [22-23]. 


\section{Oxide CMC mechanical and thermal properties comparison}

After classifying the different types of oxide CMCs, a more specific comparison of their mechanical, thermal, would allow for a better clarification in which cases these materials could also be used for Aero-engine applications. This objective was accomplished by creating mechanical and thermal properties comparison charts, known as well as Ashby Charts, in the CES-Edu pack program.
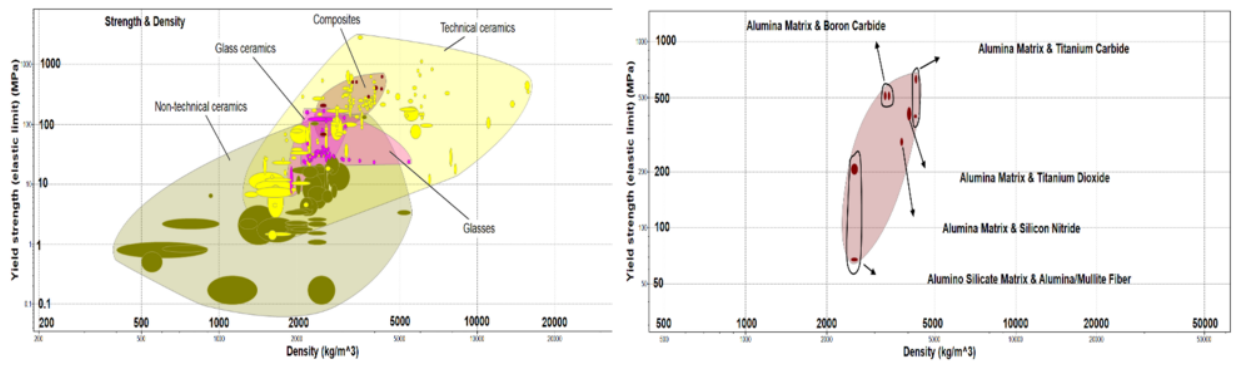

Figure 2 Classification of O-CMC materials against Ceramics in terms of Yield Strength vs Density.
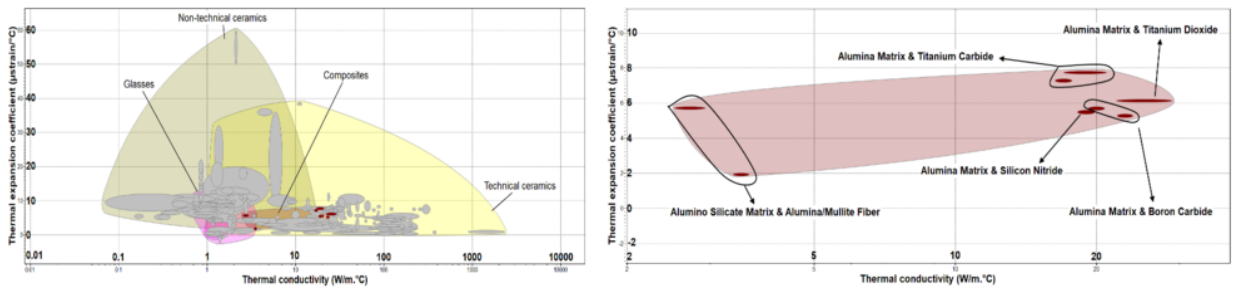

Figure 3 Classification of O-CMC materials vs Ceramics in terms of Thermal expansion vs Thermal conductivity.

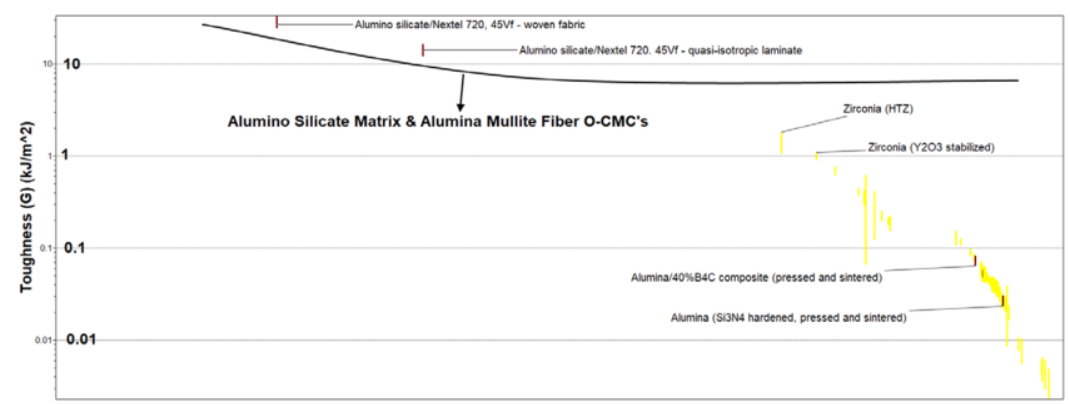

Figure 4 O-CMCs vs Ceramics Toughness $(\mathrm{G})\left(\mathrm{kJ} / \mathrm{m}^{2}\right)$ comparison chart.

Figure 2 shows the comparison of Yield Strength vs Density of the selected oxide CMCs. The materials that are on the top left side are stronger and lighter, meaning that Alumina matrix $\mathrm{B}_{4} \mathrm{C}$ is the better option for high-strength applications. Continuing with, 
Alumina matrix Titanium Carbide, Dioxide and Silicon nitride composites have very similar young's modulus results but differ in density. The less strong and light oxide CMCs are the Aluminosilicate matrix and Alumina Mullite composites

Furthermore, Figure 3 indicates the thermal properties of the selected O-CMC, compared in terms of thermal expansion vs thermal conductivity. Aluminosilicate matrix \& alumina/mullite fiber CMCs indicate the best results having the lowest thermal expansion from as well as the lowest thermal conductivity. This makes them good insulators of heat creating a sturdy char layer that protects the inner material, maintaining its integrity and slowing thermal degradation.

Figure 4 illustrates the difference in toughness between O-CMC and Ceramics, where aluminosilicate matrix \& alumina/mullite fiber CMCs have the greatest results, exceeding all the other ceramic materials, such as Zirconia ceramics and knocking down one of the most important negative attributes of ceramics in high pressure and heat applications.

According to The American Ceramic Society, the CMCs used for aerospace applications are characterized by dimensional stability over a range of temperatures and are optimized so they can allow for good mechanical strength and chemical resistance. Also, CMC materials are used in different applications according to their thermal properties. For example, materials that withstand temperatures as high as $1600^{\circ} \mathrm{C}$ are used to manufacture lightweight components that need less cooling air (e.g., vanes, blades, nozzles, combustion liners, parts of the exhaust system) [22].

\section{Potential use of O-CMCs in aeroengines}

Aerospace industry is carrying out research in the space propulsion section technology with different material concepts, trying to achieve low cost and preparation materials for their applications [26]. For propulsion systems, a great challenge is the implementation of a high thrust to mass ratio [27]. Ceramic fiber composites have been used in radiationcooled nozzle extensions as well as combustion chambers for small thrusters. In recent years, $\mathrm{C} / \mathrm{C}$ nozzles are manufactured, but several different oxide-CMC material combinations are also being tested for thrust chambers of liquid-propellant rocket engines, which have already been used for launcher propulsion systems, such as the cooling combustion chamber structures and nozzle extensions [28].

\section{Conclusions}

Summing up, oxide CMCs are a new material category that has not been used or tested in a large variety of industrial and manufacturing applications. This might be due to the very few oxide CMC material combinations that exist creating only eight different material compositions from two base material families, Alumina and Aluminosilicate/Mullite. Both oxide CMC material families have very good mechanical and thermal properties in terms of strength, weight as well as maximum temperature, and thermal conductivity, and toughness. More specifically, Alumina-based matrix O-CMCs are lighter and stronger than the aluminum silicate-based matrix ones. All in all, these observations predispose that oxides CMC's can withstand the aerospace material specification standards and that can be used in the hot section of a gas turbine aeroengine.

The next step would be the literature classification of the existing non-oxide CMC materials, which are currently used or being tested, for aero-engine applications. Furthermore, CMC manufacturing processes for both oxide and non-oxide CMCs will 
be stated. In addition, a mechanical, thermal, and physical property comparison against the oxide CMCs would be displayed by using Ashby diagrams, allowing for a better overview of their capabilities in high pressure and temperature applications.

\section{Acknowledgments}

This project has received funding from the Clean Sky 2 Joint Undertaking (JU) under grant agreement No 886840 .

\section{References}

[1] F. Raether, Ceramic matrix composites - an alternative for challenging construction tasks, Ceramic Applications $1,(2013), 45-49$.

[2] T.E. Steyer, Shaping the future of ceramics for aerospace applications, Int. J. Appl. Ceram. Technol. 3, (2013), 389-394.

[3] B. V. Ramnath, et al., Evaluation of mechanical properties of aluminum alloy-alumina-boron carbide metal matrix composites, Materials \& Design Vol. 58, (2014), 332-338.

[4] E. Rocha-Rangel, et 1., Alumina-based composites strengthened with titanium and titanium carbide dispersions, Materials Science Forum Vol. 812, (2010), 143-147.

[5] E. Refugio-García, et al., Microstructure of alumina-matrix composites reinforced with nanometric titanium and titanium carbide dispersions, Mat. Res. vol.15 no.6, (2010).

[6] Witchita State University, Composite Materials Handbook-17, SAE International, (2013), ISBN 978-0-76808108-4.

[7] V. K. Pandey, et al., Mechanical properties of Al/Al2O3 and Al/B4C composites, Advances in Materials Research, Vol. 5, No. 4, (2016), 263-277.

[8] P. Sharma, et al., Production, and some properties of Si3N4 reinforced aluminum alloy composites, Journal of Asian Ceramic Societies 3, (2015), 352-359.

[9] C.S. Ramesh, et al., Mater. Sci. Eng. 502 A, (2009), 99-106.

[10] A. Jimoh, Calculate-reinforcement of titanium matrix composites with borides, Materials Sciences and Applications, 2010.

[11] A. Farley, et al., Demonstrating the self-healing behavior of some selected ceramics under combustion chamber conditions, Smart Mater Struct 25, 2010.

[12] L. Boatemaa1, et al., The effect of the TiC particle size on the preferred oxidation temperature for self-healing of oxide ceramic matrix materials, Ceramics, J Mater, Sci 53 (2018), 5973-5986.

[13] K.M. Sree Manu, et. al., Structure, and properties of squeeze infiltrated zirconia grade-aluminosilicate short fiber reinforced aluminum composites, Journal of Alloys and Compounds, (2016), 489-499, 723.

[14] ICIS, Titanium Dioxide (TiO2) Uses and Market Data, Source: ICB Chemical Profile, 2010.

[15] R. Y1lmaz et al., Effects of TiO2on the mechanical properties of theAl2O3-TiO2plasma sprayed coating, Journal of the European Ceramic Society 27, (2007), 1319-1323, 23-785.

[16] Y. Hu, et al. European Ceramic Society 23, (2003), 691-696.

[17] M. Pelaez, et. al., A review on the visible light active titanium dioxide photocatalysts for environmental applications, Applied Catalysis B: Environmental Volume 125, (2012), 331-349.

[18] Y. Zhang, et al., Characterization of modified $\mathrm{SiC@SiO} \mathrm{S}_{2}$ nano cables $/ \mathrm{MnO}_{2}$ and their potential application as hybrid electrodes for supercapacitors Dalton Trans, Int. J. Integr. Care, 44, (2015), 19974-19982.

[19] K. Chawla, Interface engineering in mullite fiber/mullite matrix composites, J.Eur. Ceram. Soc. 28, (2008), 447.

[20] M. W. Ruggles, Mechanical Behavior of Oxide-Oxide Fiber-Reinforced CMCs at Elevated Temperature, Environmental Effects, Comprehensive Composite Materials 5, (2018), 174-236.

[21] V. K. Tushtev, et al., Assessment of three oxide/oxide ceramic matrix composites: Mechanical performance and effects of heat treatments, Compos. Appl. Sci. Manuf. 68, (2015), 19-28.

[22] Parlier, M.H. Ritti, State of the art and perspectives for oxide/oxide composites, Aero. Sci. Technol. 7, (2003), $211-221$.

[23] L. U. Gezicia, et al., The mechanical and tribological characteristics of Aluminum-Titanium dioxide composites, Revista de Metalurgia, 54, 2018.

[24] Ed. Stuart, M. Lee, Handbook of Composite Reinforcements, VCH, Cambridge, UK, 1993.

[25] M. M. Schwartz, Composite Materials Handbook, McGraw-Hill, USA, 1984.

[26] Hisaichi Ohnabea, et al., Potential application of ceramic matrix composites to aero-engine components, Composites, Part A 30 (1999), 489-496

[27] J. Alting, et al., Hot-Firing of an Advanced 40 kN Thrust Chamber, (2001), AIAA 2001-3260.

Stephan Schmidt et al., Ceramic Matrix Composites: A Challenge in Space Propulsion Technology Applications, Int.

J. Appl. Ceram. Technol. (2005), 85-96 